Kansas State Mniversity

\title{
DOE/KEURP Site Operator Program
}

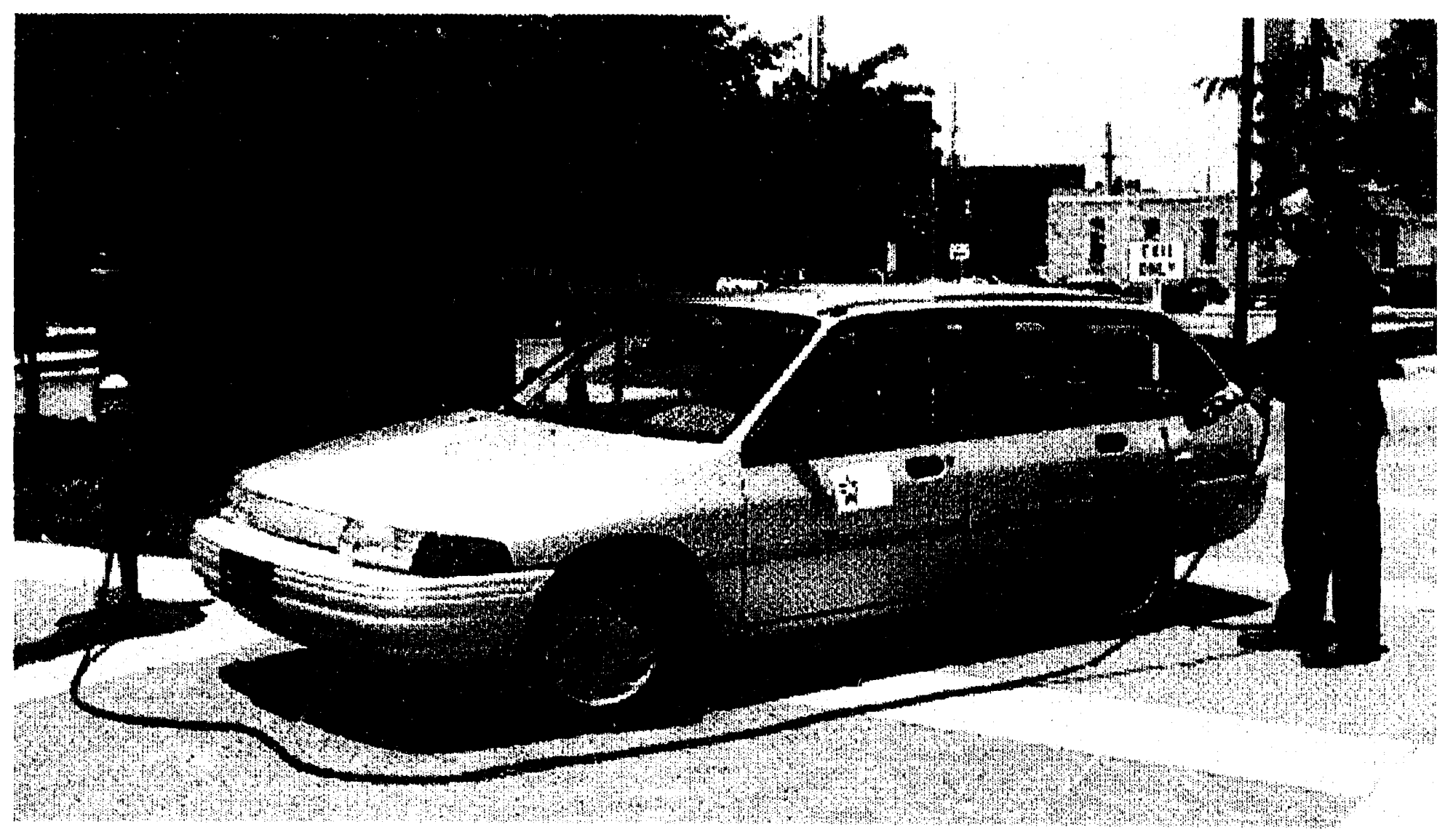

\section{Program Manager, Jim Hague}

"Plugging In" Soleq's Conversion Electric Vehicle to EHV Meter

\section{Year 3 \\ Second Quarter Report \\ October 1 - December 31 \\ 1993 \\ MASTER}


INTRODUCTION $\ldots \ldots \ldots \ldots$

Kansas State University . . . . . . . . . . . . . . . . . . . . . . . . . . . . . . . 2

College of Engineering . . . . . . . . . . . . . . . . . . . . . . . . . . . . . . . . . 3

Kansas Electric Utilities Research Program . . . . . . . . . . . . . . . . . . .3

ICE Corporation . . . . . . . . . . . . . . . . . . . . . . . . . . . . . . . 4

Hancock Electric Motor, Inc. . . . . . . . . . . . . . . . . . . . . . . . . .4

EHV Corp . . . . . . . . . . . . . . . . . . . . . . . . . . . . . . . . .5

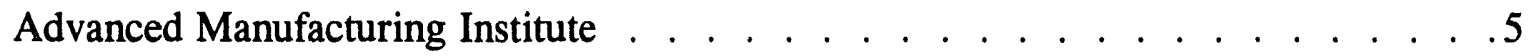

KPL, A Western Resources Company. . . . . . . . . . . . . . . . . . . . . .5

PROGRAM PLAN . . . . . . . . . . . . . . . . . . . . . . . . . . . . . . . . . 6

Short Term Goals . . . . . . . . . . . . . . . . . . . . . . . . . . . . . . . . 6

Long Term Goals . . . . . . . . . . . . . . . . . . . . . . . . . . . . . . . . 6

SIGNIFICANT EVENTS/MEETINGS/PUBLICITY . . . . . . . . . . . . . . . . .

PRESENTATIONS . . . . . . . . . . . . . . . . . . . . . . . . . . . .7

Second Quarter . . . . . . . . . . . . . . . . . . . . . . . . . . .7

Third Quarter (scheduled). . . . . . . . . . . . . . . . . . . . . . . . . . . 8

MEDIA EVENTS . . . . . . . . . . . . . . . . . . . . . . . . . 9

Second Quarter . . . . . . . . . . . . . . . . . . . . . . . . . . . . .9

Third Quarter (scheduled). . . . . . . . . . . . . . . . . . . . . . . . . . . . . . . 9

MEETINGS . . . . . . . . . . . . . . . . . . . . . . . . . . . . . . . . 10

Second Quarter . . . . . . . . . . . . . . . . . . . . . . 10

Third Quarter (scheduled). . . . . . . . . . . . . . . . . . . 11

VEHICLES/COMPONENTS/BATTERIES . . . . . . . . . . . . . . . . . . . 12

Conceptor G-Van ． . . . . . . . . . . . . . . . . . . . . . . . . . . . . . 12

Soleq EVcorts . . . . . . . . . . . . . . . . . . . . . . . . . . . . . . . . . . . . . . . . . 12

DSEP Chrysler Minivan . . . . . . . . . . . . . . . . . . . 13

OPERATIONS/ACTIVITIES . . . . . . . . . . . . . . . . . . . . . . . . . . . . . 14

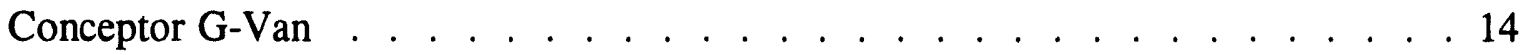

Soleq EVcort ． . . . . . . . . . . . . . . . . . . . . . . . . . . . . . . . . . . 15

PROCUREMENT OF NEW VEHICLES $\ldots \ldots$. . . . . . . . . . . . . . . . . 17

Chevrolet S-10 Vehicles. . . . . . . . . . . . . . . . . . . . . . . . . . 17

SUMMARY/CONCLUSION . . . . . . . . . . . . . . . . . . . . 18

APPENDIX A . . . . . . . . . . . . . . . . . . . . . . . . . . . . . . . . . . . . . . . 19

Mid-American Manufacturing Technology Center Report . . . . . . . . . . . . 19 


\section{INTRODUCTION}

\section{Kansas State University}

Kansas State University was founded in February 1863 as a land-grant institution under the Morrill Act. It has evolved into an internationally reccgnized comprehensive university. Kansas State University offers excellent academic programs, a lively intellectual and cultural atmosphere, and a friendly campus to its community of approximately 17,500 undergraduate and 3,500 graduate students.

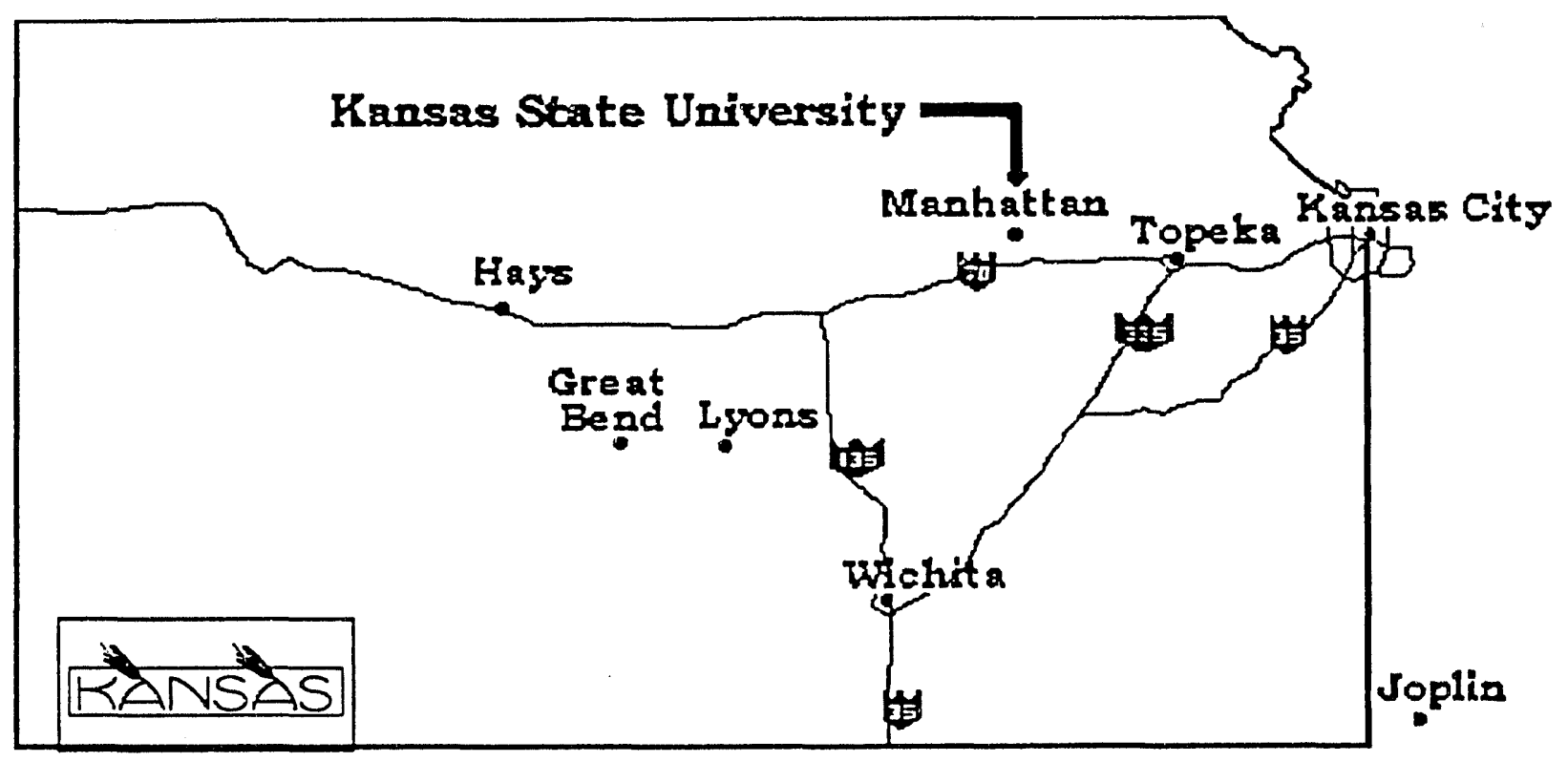

The 668-acre main campus is located in northeastern Kansas. Manhattan is approximately fifty miles to the west of the state's Capital of Topeka and eighty-five miles west of Kansas City. The university offers more than 200 undergraduate degree programs, 60 master's degree programs, and 42 doctoral programs within its eight colleges: agriculture, arts and sciences, architecture and design, business administration, education, engineering, human ecology, and veterinary medicine.

$\mathrm{K}$-State accomplishments have had extensive effects: astronaut space gloves and the waterpurifying system used on the NASA space shuttles were developed here; two Kansas Centers of Excellence, one in manufacturing and one in value added research are located on campus; the University has national hazardous substance and atomic physics research programs; the Konza Prairie Research Natural Area is used for a National Science Foundation ecological research study on erosion and prairie mammals; and a major national center for basic cancer research is at $\mathrm{K}$ State.

Paul Harvey labeled Kansas State University the "student scholar capital of the world." This statement was made based on the number of Rhodes, Truman, Fulbright, Mellon, Goldwater, Phi Beta Kappa, Rotary International, Javits, Tilden-Snow, and Marshall scholarships awarded to KState students over the past sixteen years. 


\section{College of Engineering}

The College of Engineering at Kansas State University has excellent programs in every aspect of engineering. The college has an enrollment of 2,600 undergraduates and 300 graduate students. K-State offers degrees or options in almost every major

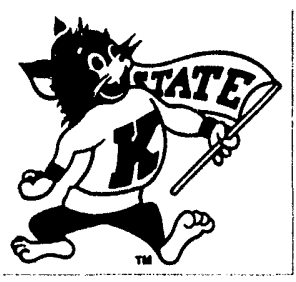
field of engineering, including aerospace, agricultural, architectural, biomedical, chemical, civil, computer, construction science, electrical, engineering technology, industrial, manufacturing, mechanical, and nuclear.

Kansas State's College of Engineering is recognized nationally for the quality of both its students and faculty. Approximately half of all K-State's National Merit Scholarship finalists enroll in the college.

For six consecutive years, one or more K-State students have been selected for Washington, D.C. internships in the Engineering Program. Each year WISE selects a group of only 14 to 16 engineering students from more than 200 engineering colleges across the nation. These students work on engineering and technology public policy issues.

Ray Dempsey, a senior in industrial engineering, was selected as the 1989-90 outstanding black engineer by the National Society of Black Engineers.

K-State's College of Engineering is one of 10 colleges in the country to be cited twice by the National Society of Professional Engineers for its outstanding professional programs. The chapters of the departmental professional sectors have received national recognition. Most recently, agricultural engineering, civil engineering, and construction science have been designated as the outstanding student chapters in the nation.

\section{Kansas Electric Utilities Research Program}

Formed on July 15, 1981, the goal of this program is to undertake applied research and development projects that may enhance reliability and minimize the cost of electric service in Kansas. The Kansas Electric Utilities Research Program (KEURP) is a contractual joint venture between six major electric utilities that serve the residents of the State of Kansas:

KPL, A Western Resources Company, Topeka, Kansas

Kansas City Power \& Light Company, Kansas City, Missouri

KG\&E, A Western Resources Company, Wichita, Kansas

WestPlains Energy, Great Bend, Kansas

The Empire District Electric Company, Joplin, Missouri

Midwest Energy, Inc., Hays, Kansas

The establishment of KEURP was made possible by the Kansas Corporation Commission (KCC). The KCC allowed Kansas electric uitities to include research and development (R\&D) costs in 
their operating expenses, including dues to the Electric Power Research Institute (EPRI).

Kansas' universities play a unique role in KEURP with representation on the executive, technical and advisory committees of the program. The universities receive significant direct and indirect support from KEURP through direct funded projects as well as KEURP/EPRI co-funded projects. KEURP is working with EPRI researchers on projects to develop or expand Kansans' knowledge and expertise in the fields of high technology and economic development. KEURP is a major source of funding in the electric/hybrid vehicle demonstration program.

\section{ICE Corporation}

ICE Corporation is an original equipment electronics manufacturer. Seventeen employees produce solid state and microprocessor control systems for the aircraft, agriculture,

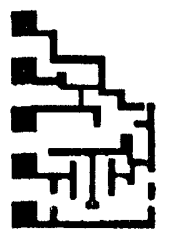
and oil industries. Complete design and manufacturing facilities are located in Manhattan, Kansas.

ICE Corporation was one of seven Kansas companies awarded an SBIR grant from the Federal Government. The grant, from the U.S. Army Small Business Innovation Research Program for $\$ 436,000$, was earmarked to complete Phase II of ICE's research of high technology power switches. The switches may be used in anything from a computer to an automobile. These switches have ratings as high as 400 dc volts at 100 amperes and yet are only the size of a standard business card. ICE has provided $\mathrm{KSU}$ with a $\$ 2,000.00$ per year written commitment in support of KSU's FHV demonstration program.

\section{Hancock Electric Motor, Inc.}

Hancock Electric Motor (HEM) is one of the largest electric motor repair facilities in the state of HanCOCK $\begin{aligned} & \text { Kansas. The shop facilities in Lyons, Kansas, contain a welding shop } \\ & \text { (metalizing, welding, and chroming facilities), machine shop (500 ton } \\ & \text { horizontal press, } 250 \text { ton vertical press, horizontal boring machine, and a }\end{aligned}$ 60 -inch engine lathe), dynamic balancing, vacuum pressure impregnation system, and capabilities to rewind electric motors with 13,200 volt 10,000 horsepower ratings. AC motors, DC motors, synchronous motors and generators, pumps, traction motors, locomotive main generators, alternators, generators, semihermetic motors, and haul truck wheel motors are all within the realm of HEM's repair capability. Further impedance testing can be done with the $750 \mathrm{KVA}$ core loss tester. Labor rates run $\$ 40 /$ hour with design and consulting costs at $\$ 75 /$ hour plus expenses. HEM is cornmitted to helping KSU in EHV demonstration, research, testing, and evaluation and has provided a letter of commitment for $\$ 2,000.00$ per year for the life of DOE's contract. HEM has recently taken steps to allow production of electric vehicles to meet growing market demands within the Midwest region. 


\section{EHV Corp}

EHV Corp is a Kansas Company specializing in manufacturing infrastructure components for the electric vehicle industry. The home office of EHV Corp is located in Manhattan, Kansas. Manufacturing of electrical and mechanical parts is accomplished by other companies while EHV Corp is primarily concerned with the research and development of new products and the assembly of existing products. EHV Corp has received an economic development grant from the state of Kansas for development of its EDD-7 charging station.

Further, EHV Corp has developed proposals to DOE and EPRI concerning its products. EHV Corp recently delivered its first meter for testing by a governmental laboratory. EHV Corp is hoping to establish a national demonstration program for curbside recharging within the next twelve months. This project would involve the Federal Government, Underwriters Laboratory, and major utilities in establishing curbside charging stations in major urban centers. EHV Corp has provided a letter of commitment for $\$ 10,000.00$ to establish this national demonstration program.

\section{Advanced Manufacturing Institute}

The Advanced Manufacturing Institute (AMI) was established to promote technology transfer in the state of Kansas. AMI's goal is to develop and transfer new

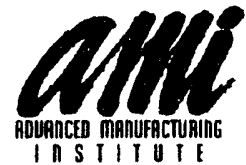
technology to commercial manufacturers. This Center of Excellence, located in the College of Engineering, is funded by the Kansas Technology Enterprise Corporation that derives its funding through the state lottery system. AMI strives to increase economic development through research and technology transfer in advanced areas of manufacturing technology. The institute's objectives are to assist Kansas companies by working with them to expand services, design new products, and increase productivity. Special emphasis is given to the needs of smaller companies.

\section{KPL, A Western Resources Company}

Kansas Power and Light Company is part of Western Resources. Western Resources supplies electricity and natural gas to most of Kansas and portions of

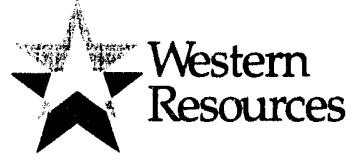
Missouri and Oklahoma. Although KPL provides funding to KState's electric vehicle program through its membership in KEURP, it provides additional funding directly to K-State in support of electric vehicle programs. KPL has been involved with K-State during the last fifteen years in providing support for electric vehicles. KPL engineers are working with K-State to develop a national demonstration program to evaluate infrastructure technology for electric vehicles. 


\section{PROGRAM PLAN \\ Statement of Objectives}

\section{Short Term Goals (1 year)}

1. Participate in the Department of Energy's Site Operator Program.

2. Evaluate Electric/Hybrid Vehicle technology through purchase of vehicles.

3. Collect user data and develop historical perspective on vehicle requirements.

4. Provide reports to DOE and KEURP on data collected.

\section{Long Term Goals ( 5 years)}

1. Assist the nation in reversing environmental trends concerning air quality.

2. Assist major urban centers in reducing air pollution.

3. Apply and develop technological enhancements to electric/hybrid vehicles.

4. Assist Kansas-based companies in developing vehicle and infrastructure subsystem components for commercial application.

Kansas State University, with funding support from federal, state, public, and private companies, is participating in the Department of Energy's Electric Vehicle Site Operator Program. Through participation in this program, Kansas State is displaying, testing, and evaluating electric or hybrid vehicle technology. This participation will provide organizations the opportunity to examine the latest EHV prototypes under actual operating conditions. KSU has purchased several electric cars and proposes to purchase additional electric vehicles. KSU has purchased one G-Van built by Conceptor Industries, Toronto, Canada and has procured two (2) Soleq 1993 Ford EVcort station wagons. During calendar year 1994, the Kansas' electric vehicle program expects to purchase a minimum of four and a maximum of eleven additional electric vehicles.

The G-Van was signed in order for the public to be aware that it was an electric vehicle. Financial participants' names have been stenciled on the back door of the van. The Soleq EvCorts have not been signed. In order to demonstrate the technology as feasible, the EvCorts were deliberately not signed. The goal is to generate a public perception that this vehicle is no different from any similar internal combustion engine vehicle. Magnetic signs have been made for special functions to ensure sponsor support is recognized and acknowledged. 


\section{SIGNIFICANT EVENTS/MEETINGS/PUBLICITY}

\section{PRESENTATIONS}

\section{Second Quarter}

October 11

October 14

October $25-28$

November 12

November 19
Fort Riley Elementary School

Manhattan, $K S$

Professor Hague, at the request of Fort Riley's Technology program presented an hour program on electric and hybrid vehicle technology to three different eighth grade classes. Students were asked to write a report on the environment and the impact electric vehicles would have. Faculty members chose the best reports and those students were given rides in the $\mathrm{K}$-State electric vehicle.

Beech Aircraft

Wichita, KS

Professor Hague and Mrs. Jean Waters visited with Beech engineers to discuss possible advanced technology design electric vehicles. Beech Aircraft, which is based in Wichita, has already been contacted by Ford Motor Company about possible advanced vehicle design projects. Further, as part of an ARPA project, Beech Aircraft is working with Georgia Tech on a bus project. Beech was very receptive and interested in Kansas State University's electric and hybrid vehicle program and further talks are planned between both organizations.

Fort Leavenworth

Leavenworth, $K S$

Western Resources, Inc., presented an electric vehicle slide show to a number of different schools in Leavenworth. K-State's Soleq EvCort was to be on display during the presentations but, due to logistical problems the vehicle was not used. Media coverage was available from both the school and local newspaper coverage.

Logan Junior High School

Topeka, $K S$

Western Resources, Inc., Wade Graves, presented an electric vehicle demonstration to Logan Junior High School's seventh grade class. Wade presented information about the future of electric vehicles and took students and faculty members for a ride in the Soleq EvCort.

QuailRun Elementary School

Lawrence, $K S$ Western Resources, Inc., Wade Graves, presented an electric vehicle demonstration to QuailRun Elementary School. Wade presented a talk and vehicle demonstration to four first grade classes and their respective faculty representatives. The teachers were not comfortable with any students riding in the electric vehicle so no actual rides were given. 
Professor Hague made two presentations on alternate fuel vehicles to the honor students class. The Dean of Engineering teaches this class for engineering students having a grade point average of 3.5 or higher. The course presents a wide variety of topics and issues that will challenge the next generation of engineers. The course's purpose is to add breadth to the engineering students curriculum. Further, it is an attempt to focus the students to recognize the worldwide issues and problems which may require engineering expertise. Obviously, transportation is a worldwide system and therefore presents universal problems that requires the best engineering minds to solve.

December 4 Every year, Kansas State University hosts parents and their high school students who are thinking of attending K-State within the following year. An entire day is devoted to bringing them on campus, meeting with administrators and faculty, and touring K-State facilities. For those parents and students who may already be familiar with K-State facilities, special presentations are offered on some of the research that is currently being pursued at K-State. For the past two years, the Department of Energy's electric vehicle program has been high lighted. Professor Hague again made the presentation to over 100 participants. Significant interest is demonstrated by the parents and prospective students and it is not unusual for this fifty minute event to last several hours, especially when a drive in the electric vehicle is offered. This year, the Soleq vehicle broke down with the first demonstration drive. For those disappointed individuals, it was explained that it is better to "experience and develop" the product here on campus before it comes into the general market. Visitors were enthusiastic and requested that the electric vehicle be available each parents weekend so they could experience this new technology.

December 8

Western Resources

Topeka, KS

Western Resources held its annual marketing meeting. The electric vehicle, EHV Corp's charging station, and the Meltric plug \& cord display were all part of this annual event. Four forty-five minute sessions on EV technology were presented concurrently with NGV technology. The information was well received by interested stockholders.

\section{Third Quarter (scheduled)}

February 28

Kansas Corporation Commission

Topeka, KS The KCC is planning its annual alternate fuel program for the coming year. This year, unlike past years, the KCC has decided to take the alternate fuel program on the "road." Presently, it is planned to take a caravan of 
alternate fueled vehicles to thirty-three different cities throughout Kansas. These vehicles will be driven from city to city to demonstrate that multiple domestic fuel vehicle technology exists that can be used to diversify the Kansas' transportation system. Kansas State University is planning to participate in the alternate fuel caravan by demonstrating both electric and natural gas vehicle technology.

January 13

Manhattan High School

Manhattan, $K S$

Kansas State University will present a video and electric vehicle deomstration at Manhattan High School. The K-State Soleq EvCorts will be shown to Mrs. Simpon's Ecology class with students ranging from the freshment to senior class.the sophomore, junior, and senior high school Ecology class.

\section{MEDIA EVENTS}

\section{Second Quarter}

October 21-23

S/EV93

Boston, $M A$

Kansas State University was requested to participate in S/EV93. Further, EHV Corp was asked to display its curbside charging stations at this event. Due to previous commitments, no one from K-State or EHV was able to attend this event but brochures outlining the Site Operator Program and EHV Corp's charging station were provided to be handed out during the conference.

December $1-3$

National EPRI Convention

Scottsdale, $A Z$

Kansas State University participated in EPRI's Second National Infrastructure Convention. EHV Corp, as part of K-State's Site Operator Program displayed its curbside charger. EHV Corp's EDD-7 charging station was selected by EPRI to receive the largest cash award in the "EV Ready" category infrastructure design competition. This award was presented to EHV, Western Resources, and Kansas City Power \& Light representatives during this convention.

\section{Third Quarter (scheduled)}

No events scheduled at this time. 


\section{MEETINGS}

October $18-21$

November 15

December 1-3

December 8-9

December 8-10

December 13-15

\section{Second Quarter}

Contractor's Coordination Meeting

Dearborn, $M I$

The Automotive Technology Development Contractor's Coordination Meeting was held in Dearborn, Michigan. As Chairman of the Site Operator Users Task Force, Professor Hague presented a paper entitled, "Site Operators Program Report." Professor Hague presented this information October 21 at 11:20 a.m. Professor Hague is now finalizing the paper for submission to DOE for printing in the annual Contractor's Coordination Report printed by The Engineering Society For Advancing Mobility Land Sear Air and Space.

Entrepreneurial Center

Manhattan, $K S$

Professor Hague met with John Walters, Director, Kansas State University Entrepreneurial Center to discuss EHV Corp and its patented charging station. Discussions were focused on present and new patents EHV Corp has or is obtaining to protect infrastructure components now being developed.

EPRI Meeting

Scottsdale, $A Z$ Professor Hague attended the Second Annual Electric Power Research Institute Seminar. Professor Hague attended this seminar with representatives from Western Resources and Kansas City Pover \& Light utility companies.

FFCTF Meeting

Washington, $D C$ Professor Hague attended the Federal Fleet Conversion Task Force meeting. At this meeting the FFCTF's initial report was officially presented to President Clinton, Vice-President Gore, and Secretary O'Leary by Gary Mauro, Chairperson of the Task Force. The Task Force is assisting the President in formulating a plan to accelerate the conversion of federal vehicles to alternate domestic fuel use.

Site Operator Users Task Force Meeting

College Station, $T X$ The SOUTF meeting was held at Texas A\&M. Responses to the SOUTF proposals for forty vehicles were reviewed with additional action items developed. The desire of the SOUTF is to issue purchase orders during first quarter 1994. Final comments and commitments are being requested from prospective suppliers.

UL Meeting/Return Soleq Electric Vehicle \#152

Chicago, IL Professor Hague met with Underwriter Laboratory representatives to discuss 


\section{December 19-21 Soleq Electric Vehicle \#152}

Chicago, IL

Two students from Kansas State University drove to Soleq's facilities in Chicago to transport the second vehicle, that had been purchased from Soleq, back to Kansas. This vehicle was officially ordered January 8, 1992. Although the vehicle is an excellent representation of electric vehicle technology, the delay in receiving the product has caused great consternation for all participants.

\section{Third Quarter (scheduled)}

January 4

KEURP Budget Meeting

Topeka, $K S$ A meeting was held with Jerry Lonergan, Director, Kansas Electric Utilities Research Program to discuss the annual budget and participation in the Department of Energies Site Operator Program. The meeting concluded in a confirmation and commitment to continue participation in the electric vehicle program with the desire to purchase a minimum of four electric vehicles during the next year.

January 24

FFCTF Meeting

Atlanta, GA The next meeting of the Federal Fleet Conversion Task Force Meeting will be held to discuss the "Green Airshed" proposal. This is a Presidential initiative that would coordinate and expedite a locally-based, grassroots process to stimulate demand for, and to integrate AFVs into, public and private fleets in targeted geographic areas beginning with federal fleets in those areas.

January $25-26$

U.L. Conference

Chicago, IL Underwriters Laboratory is holding a conference titled, "UL's Role in Electric Vehicle Safety." As Chairman of the Site Operator Program, Professor Hague will attend. The purpose of attending this meeting is both from an institutional and group perspective. Professor Hague recognizes that not all Site Operator members can be in attendance, and it is his intent to brief the SOUTF at the next quarterly meeting on information disseminated during the U.L. Conference. 


\section{VEHICLES/COMPONENTS/BATTERIES}

\section{Conceptor G-Van}

Kansas State University's G-Van, VIN 29CGG35X1MN103048, was purchased in August 1991. The G-Van is referred to by the Department of Energy's electric vehicle ID number 150 on all the maintenance reports.

The G-Van has not been driven during the reporting period. At the beginning of this period the G-Van's mileage was reduced to approximately 10-12 miles/charge. All attempts at improving the G-Van's mileage have failed. The vehicle's range continued to deteriorate, and with the advent of winter and its associated cold weather, the G-Van's range became useless. Presently, $\mathrm{K}$-State is working with a number of organizations that might be interested in repairing the G-Van to use it as a "mule" for battery testing or for use in daily routes. Since the G-Van is considered state property, the vehicle must be sold at auction before most private companies can spend any funds for repair or insurance on the vehicle. Kansas State University is in the process of advertising the vehicle for sale to the highest bidder. It is the hopes of K-State's Site Operator Program that the vehicle will be placed with an interested company that is willing to work with K-State's electric vehicle program as it upgrades or modifies the G-Van. The outcome of the bidding effort should be known by the next reporting period.

\section{Soleq EVcorts}

Of the two Soleq EVcorts, officially ordered in January 1992, one vehicle was finally delivered May 13, 1993. The second EVcort was transported to K-State December 21, 1993. The first EVcort, VIN 1FAPP15JXPW125411, will be referred to by the Department of Energy's electric vehicle ID number 151, and the second EVcort, VIN 3FAPP15J9PR106495, will be referred to by the Department of Energy's electric vehicle ID number 152 on all the maintenance reports.

Both EVcort 151 and 152 have noticeably "soft" braking. The master cylinder system was replaced on vehicle 151 in an attempt to improve braking performance. No improvement was noted. Without the use of regenerative braking on these vehicles, modifications would need to be made to increase the size of the disk or the brake pads in order to improve stopping capability. It is suspected that in an emergency stop, these vehicles might not meet safety requirements without the use of regenerative braking. Clearly, because of modifications made by Soleq in converting the vehicle to electric, it is the opinion of K-State engineers that the brakes are at the limit with increased battery weight.

EVcort 151 had a problem with the air conditioning system. Soleq rewired the compressors (two) during the vehicles visit to Chicago. Vehicle 152 is already wired so that the compressors can be operated in parallel or serial fashion. Soleq believes this will solve the compressor "kickout" problem but, until warmer weather returns it is not feasible to test the air conditioning systems of either vehicle at this time. Soleq's efforts in trying to solve the air conditioning problem is greatly appreciated. 
With the advent of colder weather, K-State has been able to evaluate the capabilities of the "electric" heating system on both vehicle 151 and 152. These three kilowatt resistive heaters work exceptionally well when operated from curbside power. It should be noted because of the heaters current draw, thirty amperes, little or no battery charging occurs during curbside heater operation. However, when the resistive heater is operated from the battery on cold to extremely cold days, the system is marginal to ineffective in keeping the interior of the vehicle warm. It is the opinion of K-State engineers that the general public would never accept the present system as adequate. When one does the calculations for a larger resistive heating system, say two to three times the present capacity, it becomes obvious that today's battery technology eliminates resistive heating systems. In fact, in all but the sunbelt regions, electric vehicle should be designed with fuel powered heaters. Such a system would conserve limited battery energy and improve universal public acceptance of such a vehicle.

EVcort 151 and 152 are being driven on a daily basis and other than previously mentioned, they both are operating in an excellent manner. The vehicles are being used on a daily basis or being used for "show and tell" on a routine basis. Public reception to the vehicle is very positive and K-State would be happy to purchase additional Soleq vehicles, if and only if, Soleq could ensure delivery on a much more timely basis.

\section{DSEP Chrysler Minivan}

Kansas State University received this vehicle in early February, 1993. The purpose of K-State accepting this vehicle was to obtain an experimental electric vehicle designed around a Chrysler minivan. The dual shaft electric propulsion (DSEP) minivan was built under contract by Eaton Corporation in 1987. The minivan's VIN is $187 \mathrm{GK} 14 \mathrm{~K} 0 \mathrm{HX} 100100$ and will be referred to by the Department of Energy's electric vehicle ID number 153 on all future maintenance reports. Kansas State University planned to revitalize the vehicle and make it part of the demonstration program. Upon receipt and after taking inventory, it was determined that it would cost more than the vehicle was worth to bring it back to full operational capability, as it was originally designed. At present, K-State has had discussions with a utility company and a battery company about assisting in using the vehicle as a battery testing platform.

$\mathrm{K}$-State is in the process of taking bids on this vehicle. It is expected that during the next quarter the vehicle will be provided to the highest bidder. K-State has been working with several companies interested in bidding and restoring the minivan to a useful state. As soon as bids have been received and a final determination can be made on the winning bid, $\mathrm{K}$-State will be able to report on the future of this vehicle. 


\section{OPERATIONS/ACTIVITIES}

\section{Conceptor G-Van}

The Conceptor G-Van, DOE number 150, has not been operated during this reporting period. The van is presently stored in the College of Engineering's main building. Discussions with the City of Overland Park, Kansas City Power \& Light, and Kansas State University are being held to determine the most cost effective means of repairing this vehicle and getting it back out on the street in routine use. No federal funds will be used to repair this vehicle.

The G-Van, when used, is charged indoors in a temperature controlled environment. The ambient charging temperature for this vehicle is 70 to 80 degrees Fahrenheit. The vehicle is occasionally charged in other less controlled environments as it is being demonstrated around the state. During demonstrations and shows the vehicle is not driven extensively, instead it serves as a static display. Valuable data does not exist during these demonstration periods, therefore charging conditions cannot be evaluated. Table 1 gives a general review of the data collected on the Conceptor G-Van operated during this reporting period.

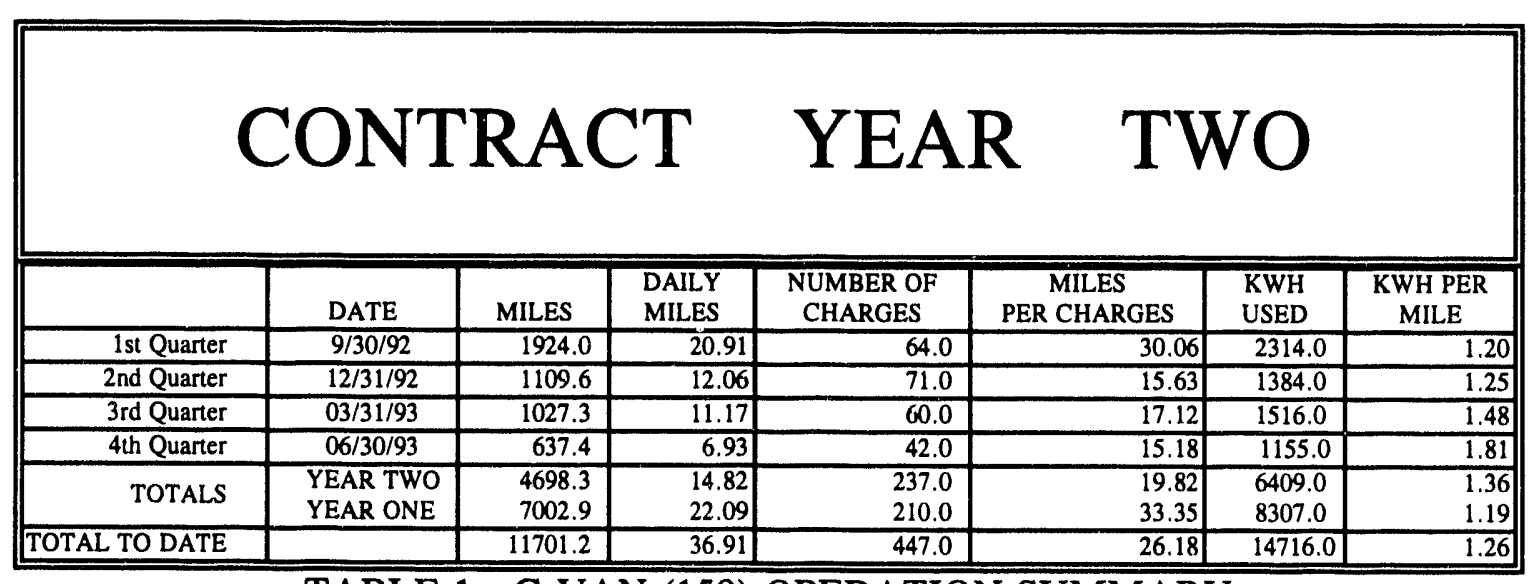

TABLE 1. G-VAN (150) OPERATION SUMMARY

Assuming a price of $\$ .05 / \mathrm{kWh}$ for electricity, and $16 \mathrm{mpg}$ for the internal combustion engine GMC Vandura, the cost of operating the G-Van on electricity equates to $\$ 1.00$ per gallon of gasoline. 


\section{Soleq EVcort}

The Soleq EVcort, DOE number 151, has been operated regularly since it was received in May. The vehicle has been displayed at various locations throughout the area this quarter. Included were shows to area high schools and junior high schools. The vehicles participation was sponsored by Kansas State University and Western Resources to promote electric powered vehicles. The vehicle experienced a problem with the DC to DC converter causing vehicle failure during a demonstration at Kansas State University. Soleq, in order for the vehicle to meet other demonstration deadlines, shipped Kansas State a replacement converter. Due to this malfunction, the Soleq EVcort (151) was taken back to Chicago for maintenance and a routine "check up." Because of this interruption, the EVcort (151) has not been driven regularly since late November.

The Soleq Vehicle, due to its onboard charger, is not only driven in various weather conditions, but is also able to be charged in these conditions. A student assistant uses the vehicle as he would his own "gas" (internal combustion) powered vehicle. The vehicle is charged and stored in his garage and is subjected to normal everyday driving in and around the Manhattan area. The vehicle performs comparable to the standards of the average "gas" powered vehicle. Table 2 gives a general look at data collected on the EVcort to this point.

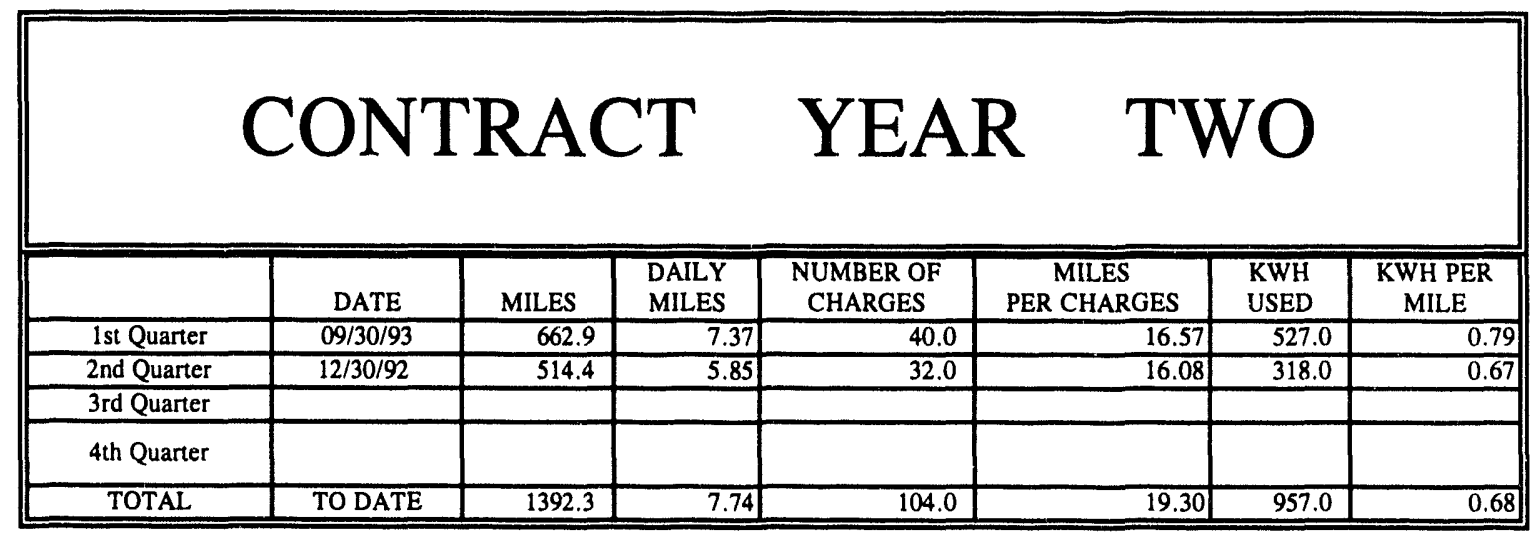

TABLE 2. EVcort (151) OPERATION SUMMARY

Assuming a price of $\$ .05 / \mathrm{kWh}$ for electricity, and $25 \mathrm{mpg}$ for the internal combustion engine 1993 Ford Escort, the cost of operating the EVcort on electricity equates to $\$ .85$ per gallon of gasoline. 
Although significantly late, the Soleq EVcort, DOE number 152 , has recently become a part of Kansas State's electric vehicle program. In order to expedite the process, two student assistants were sent to Chicago's Soleq Corporation to haul the vehicle back to Manhattan. After reaching Soleq, the students found Soleq to be running still more tests on vehicle. Nevertheless, the students reached Manhattan with the new vehicle December 20, 1993. Due to this recent arrival, specific data on vehicle performance has yet to be acquired. During the next quarter the vehicles performance characteristics will be accurately compiled.

\begin{tabular}{|c|c|c|c|c|c|c|c|}
\hline & DATE & MILES & $\begin{array}{l}\text { DAILY } \\
\text { MILES }\end{array}$ & $\begin{array}{l}\text { NUMBER OF } \\
\text { CHARGES }\end{array}$ & $\begin{array}{c}\text { MILES } \\
\text { PER CHARGES }\end{array}$ & $\begin{array}{l}\text { KWH } \\
\text { USED }\end{array}$ & $\begin{array}{l}\text { KWH PER } \\
\text { MILE }\end{array}$ \\
\hline 1st Quarter & & & & & & & \\
\hline 2nd Quarter & $12 / 30 / 92$ & 147.7 & & & & 78.0 & 0.53 \\
\hline 3rd Quarter & & & & & & & \\
\hline \multicolumn{8}{|l|}{ 4th Quarter } \\
\hline TOTAL & TO DATE & 147.7 & & & & 78.0 & 0.53 \\
\hline
\end{tabular}

TABLE 3. EVcort (152) OPERATION SUMMARY 


\section{PROCUREMENT OF NEW VEHICLES}

\section{Chevrolet S-10 Vehicles}

Kansas State University, in participation with the Department of Energy expects to purchase a minimum of four Chevy S-10 vehicles that will be converted by Spartan Motors in conjunction with General Electric Corporation. These vehicles will demonstrate advanced AC drivetrain technology, including both controller and motor system. Further, GE, in partnership with Spartan Motors, is working on a thermal battery management system to ensure a minimum of sixty miles of driving range irrespective of the outside temperature. These vehicles will be placed at four of the six utilities now participating with KEURP. Delivery date for these vehicles is expected late summer 1994. 


\section{SUMMARY/CONCLUSION}

K-State has concluded the second quarter of the third year, demonstrating and evaluating electric vehicle technology. The G-Van has failed to operate during this period. Plans are being made to dispose of both the Conceptor G-Van and the Chrysler minivan. These vehicles have little to prove or demonstrate in the way of advanced technologies and it is cost prohibitive for K-State to repair the vehicles at this time.

Kansas State University is using and pleased with both Soleq EVcorts. These vehicles have been used on a routine basis around campus, at the Nebraska State Fair, the Kansas State Fair, and other specific public demonstrations. The vehicles continue to operate in an efficient manner, are well received by the public, and clearly demonstrate what is possible in EV technology.

During this reporting period Professor Hague served on a Presidential Task Force concerned with converting the federal fleet of vehicles to alternate fuels. Professor Hague continued to serve as the Chairman of the Site Operator Users Task Force. As such, KState is involved at all levels in promoting electric vehicle legislation and technology. The electric vehicle technology continues to be debated and discussed at all levels of government. It is hoped that government recognize, if any alternate fuel vehicle program is going to be successful in establishing itself in the marketplace, improvements in federal funding for specific programs will be necessary. The SOUTF has established an effort to "push" the EV technology forward with the development of a common specification to be used in the purchase of electric vehicles during this next year. Hopefully, the "players" involved in this process will improve the national opportunity to prove that an electric vehicle market exists and is achievable in incremental steps.

In conclusion, this quarter has proven to be full of important activities for Kansas State University. New program opportunities are continually being looked into. All participants in the Site Operator Program will continue to work with the Department of Energy and its national laboratories in bringing better electric vehicle technology to the marketplace. 


\section{APPENDIX A}

Mid-American Manufacturing Technology Center Report 
SPONSORS:

Mid-America Manufacturing Technology Center

Department of Energy's Site Operator Program

Kansas State University

\section{PRINCIPAL INVESTIGATOR:}

James R. Hague

Associate Professor

MAMTC REPRESENTATIVE:

Gary Latham

Field Engineer

\section{STUDENT ASSISTANT:}

Richard Rodgers

Mechanical Engineering Technology

\section{PROJECT START DATE:}

June 14, 1993

\section{PROPOSED PROJECT COMPLETION DATE:}

January 15, 1994 


\section{TABLE OF CONTENTS}

DESCRIPTION OF CONTRACT $\ldots \ldots \ldots \ldots \ldots \ldots \ldots$

OBJECTIVE OF PROJECT $\ldots \ldots \ldots \ldots \ldots \ldots \ldots$

KSU/MAMTC/KANSAS MANUFACTURING/PROJECT RELATIONSHIP . . . . . . . 3

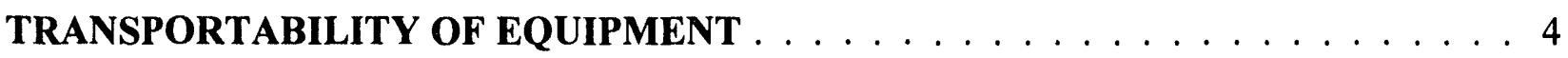

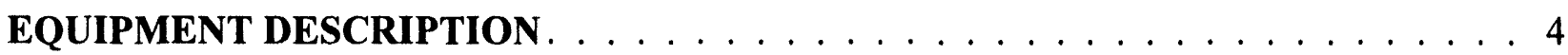

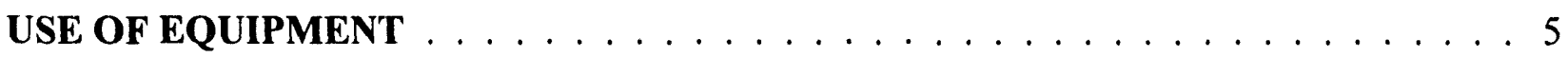

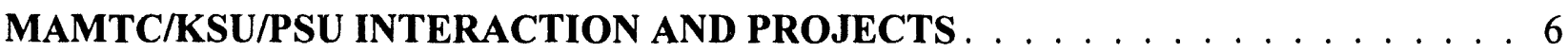

MODIFICATION OF EQUIPMENT $\ldots \ldots \ldots \ldots \ldots$

GOALS/PROJECTS UNDERTAKEN/AND FUTURE PROJECTS $\ldots \ldots \ldots \ldots$

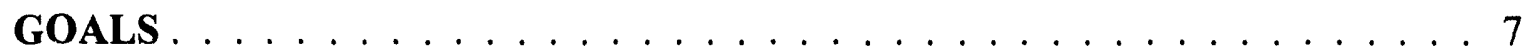

PROJECTS UNDERTAKEN $\ldots \ldots \ldots \ldots \ldots$

FUTURE PROJECTS . . . . . . . . . . . . . . . . . . . . . . . . . . . 10

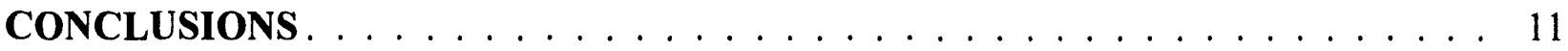

DESIGN (WORKSTATION) COMPUTER SYSTEM . . . . . . . . . . . . . . . 12

CAMM-3 CONTROL COMPUTER SYSTEM . . . . . . . . . . . . . . . 12

APPENDIX A (continued) $\ldots \ldots \ldots \ldots \ldots \ldots$

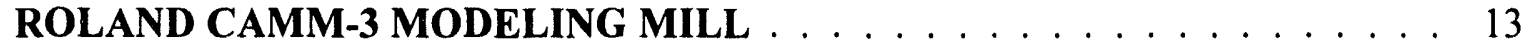

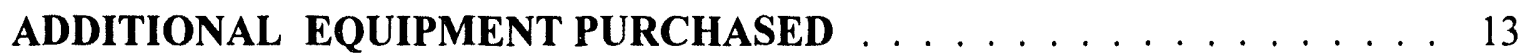

APPENDIX B $\ldots \ldots \ldots \ldots \ldots \ldots \ldots$

PROJECT SOFTWARE $\ldots \ldots \ldots \ldots \ldots \ldots \ldots$

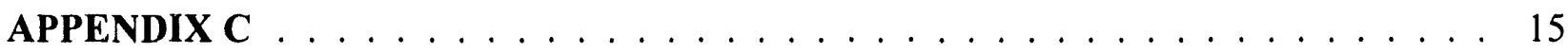

CONTRACT PROPOSAL FUNDING CATEGORIES . . . . . . . . . . . . 15

FUNDS EXPENDED TO DATE . . . . . . . . . . . . . . . . . . . . . . . 15 


\section{DESCRIPTION OF CONTRACT}

The contract was awarded to the Principal Investigator, Professor James R. Hague, to purchase a portable computer aided modeling machine and other necessary equipment. This equipment will be evaluated for its potential to assist MAMTC engineers, K-State faculty and students, and Kansas' manufacturers during prototype design, pre-production modeling and fabrication of components. Because of the high cost associated with prototype design and the significant capital investment required to establish such capabilities, a cost-effective modeling machine has the potential of ensuring that small manufacturers remain competitive in bringing new products to market.

MAMTC and K-State co-funded this project. The project includes funds for student salary and the purchase of equipment. The equipment listed as part of the contract is shown in Appendix C. Since the contract was awarded, several modifications have been made to the equipment purchased. Even though the Principal Investigator has re-directed funding, no change in the overall budgeted funds has or will be requested from MAMTC or K-State. The changes in scope (equipment purchases) have occurred for a number of reasons. The Principal Investigator found a way to purchase additional accessory items through cost reduction efforts. Some equipment necessary for proper and safe operation was not included as part of the original project proposal. Additional purchased equipment will make the proposed equipment purchases more fiexible to meet the goals of this project. Changes are discussed throughout the text of this document as they pertain to the different operations.

\section{OBJECTIVE OF PROJECT}

The main objective of this project was to define, setup, and utilize a cost-effective "preproduction" modeling and design assistance tool for small businesses in Kansas. By using the Roland CAMM-3 Modeling Machine as an intermediary between the "paper design" and final production, Kansas' small manufacturers can actually work with scale or full size models of new products before committing financial resources to full production. Using the CAMM-3 modeling machine as an intermediate step in the manufacturing process offers the advantage of minimizing scheduling problems and provides the manufacturer with greater control and flexibility in the research and development effort. This will ensure that manufacturer's remain competitive.

A simple example will help illustrate what is being accomplished with this project. Almost all agricultural products require some form of electronic controls interfaced with mechanical systems. A computer aided modeling system can impact product development in two areas: (a) in the prototyping of one-of-a-kind or pre-production circuit board fabrication and (b) in prototyping and developing scale models of mechanical interfaces. Further, small manufacturers who have access to cost effective modeling equipment have control of the product's "destiny." As the design, prototype, and development stages occur, the manufacturer can quickly correct errors and ensure the process continues according to the manufacturer's schedule. Third party assistance is minimized until the merchandise is ready for production. 
Today, OSHA and other federal agencies regulate safety in the work place, especially in the fabrication of electronic circuit boards, hazardous chemicals and critical processes. For the small manufacturer, se iting up even a small circuit board fabrication facility can be costly. Failing to maintain the circuit board fabrication facility properly will ensure an opportunity for both fines and potential liability; therefore, the small manufacturer is forced to use an outside source for small volume runs. The manufacturer is forced to pay higher initial costs until full production runs are realized. Further, these same small manufacturers now have to deal with scheduling problems when they look to others for support. The use of low-cost prototyping systems enable a reduction of design time, thereby reducing the cost associated with new product development. The manufacturer can focus more effort on research and development which will ensure a smoother transition to the production phase.

\section{KSU/MAMTC/KANSAS MANUFACTURING/PROJECT RELATIONSHIP}

The Advanced Manufacturing Institute (AMI) is an integral part of Kansas State University and the College of Engineering. AMI was established in 1990 and focuses on assisting and improving the manufacturing process for Kansas' companies. As such, AMI has purchased and uses some of the latest manufacturing software (SmartCam) and multi-axis milling machines currently available today. AMI has the capability to ensure that any design produced at K-State is ready for final production. The machines that AMI uses for these modeling processes cost literally hundreds of thousands of dollars to house, operate, and maintain. Thus, small companies have very limited routine access to this type of equipment. The CAMM-3 system has the capability to use the same software as the larger AMI machines. This virtually eliminates any reprogramming or manipulation of software files which contain the code for a specific product model. When a part is ready to be machined by the CAMM-3, the part is ready to be machined by production mills using the same data files. The CAMM-3 provides a low-cost option for making several pre-production runs and ensuring that the "part or system" is ready for final production.

It is the intent of this project to work not only with MAMTC engineers, AMI staff, K-State faculty and students, but also with the Pittsburg State University Fused Deposition Modeling Laboratory to ensure that Kansas manufacturers have the ability to go from the "drawing board" to production in a minimum amount of time at a minimum cost. Pittsburg State, along with several other support agencies, is focusing on rapid-prototyping technology. It is not the intent of this project to duplicate Pittsburg State's efforts. K-State is working with a number of Kansas companies in the area of electric vehicles, components, and subsystem development associated with this emerging technology. In order to maintain a competitive advantage, $\mathrm{K}$-State's goal is to assist Kansas manufacturers in reacting to the developing market of electric vehicles. The CAMM-3 system offers a cost-effective tool to accomplish the goal. 


\section{TRANSPORTABILITY OF EQUIPMENT}

One major advantage the CAMM- $j$ system has over larger milling machines is that it is expected to be portable. In a state such as Kansas, this portability would be viewed as a real asset. Manufacturers could be trained to use these systems and share resources and costs among themselves. This is especially important for small-town manufacturers. Remote locations make it difficult for small-town manufacturers to have access to state-of-the-art technology, training, and assistance routinely found in major urban locations. Regional or local manufacturers could work effectively to bring this technology to their areas. By helping in the development of mobile systems, Kansas State University fulfills its charter as a land-grant college. K-State provides the latest technology and know-how to those individuals and manufacturers willing to apply new equipment to new and old problems.

It is expected, once the CAMM-3 system and its associated equipment are operational, that the CAMM-3 system can be loaded into a standard vehicle or mini-van and taken on the road. As this manufacturing system is assembled, it will be evaluated for its capability to remain transportable.

\section{EQUIPMENT DESCRIPTION}

1) A Roland Corporation CAMM-3 digital mill was purchased. This mill is a fully capable three-axis milling and drilling system. It is capable of milling "soft" materials (other than steel or iron) in sizes up to 7" x 6" x 6". Mill operations are controlled by an external computer that is used to transfer data files to the mill's internal computer.

2) A $486 \mathrm{DX} / 2-66$ computer system has been purchased. This computer system will be used as a design station for producing design drawings in Autocad and SmartCam. This computer contains 32 megabytes of random access memory, has dual floppies, multiple input/output capabilities, a 330 megabyte hard disk drive, and a tape backup system. Large amounts of memory and hard disk space are required to handle significant amounts of data that are generated during the model design.

3) A $486 \mathrm{DX} / 2-50$ computer system has been purchased. This computer system will be used as the CAMM-3 control system. Once all design work has been completed at the design station, described in item 2 above, the control computer will handle communications and transfer of data to the CAMM-3 system. This computer contains 32 megabytes of random access memory, has dual floppies, multiple input/output capabilities, a 4 megabyte hard disk cache controller with a 170 megabyte hard disk drive, and a tape backup system. The sophisticated hard disk controller ensures maximum transfer rates of large amounts of data to the CAMM-3 system. Although the use of separate computer systems for the design and control functions appears redundant, in the University environment the second computer system ensures maximum productivity of the faculty and students who use this equipment. Hopefully, this will ensure that this project will accomplish more tasks and achieve more goals in the allotted time. 
4) A number of accessory items have been purchased to improve the CAMM-3's potential. Several end mills and drill bits have been purchased to use with the mill. A drill chuck and shank have also been purchased to give the mill drilling capabilities. These items will increase the flexibility of the CAMM-3 system in both the mill and drill operation.

5) A dust collector was purchased for this system. The dust collector keeps the area adjacent to the CAMM-3 free of debris and thus provides a safer work environment. The major advantage of a dedicated dust collector system, over the commercial shop vacuum recommended by Roland Corporation, is increased vacuum and significantly reduced cost.

6) This project has purchased a Hewlett-Packard Design Jet 650C plotter with a 16 Mbyte memory upgrade. This plotter is used as a "paper draft" to verify accuracy and design before the first prototype is generated. Hard copies serve to correct errors before and after the prototype process has been started. Further, hard copies serve to provide the small manufacturer with final drawings that will be used in the production phase.

7) Software locks for SmartCam software have been purchased. Computer software locks are commonplace in the industry. These locks ensure only authorized personnel have access to legal copies of production software. The locks attach to the parallel or serial port connectors of the control computer. These locks must be installed on the computer before the SmartCam software can be operated. A lock has been purchased for each of the two computers now being used as part of this project.

8) The purchase of 3 ADEX 20" color monitors have been made for the project. These monitors are of high quality. One of these monitors has been on loan from the manufacturer since September. Throughout this period the monitor has preformed exceptionally well in Windows, Autocad and SmartCam environments, running at a resolution of 1280 pixels by 1024 pixels and 800 pixels by 600 pixels. The monitor has provided an excellent graphics device for the computer, and has the additional bonus of low cost ( $\$ 730.00$ per unit).

\section{USE OF EQUIPMENT}

The contract, approved by MAMTC, provided for the purchase of one computer to be utilized in this project. Once the CAMM-3 modeling machine was received its capabilities were evaluated. It was decided, because of the CAMM-3's limited storage buffer ( 5 Kbyte), that another computer would be needed to control the CAMM-3 and a separate computer would be used for design work. This dual computer system is more efficient because certain CAMM-3 milling operations can take several hours to complete. During this modeling process, the computer system is tied up. With a second computer available, students and faculty can be more productive. The dual computer system was established out of necessity to ensure maximum efficiency in minimum time but, it did add considerable cost to the project. Depending on the manufacturer, it is expected that others who purchase the CAMM-3 system might want to buy a second computer or find a way to "dump" software code to "free-up" the design computer. 
Kansas State University's Department of Engineering Technology and the Department of Energy's Site Operator Program contributed resources that allowed the Principal Investigator to provide two computers for this project. The computer systems only addition was a large high resolution monitor and 16 Mbytes of random access memory, which improved system performance when running the complex software packages required in the modeling process.

\section{MAMTC/KSU/PSU INTERACTION AND PROJECTS}

One of the requests made by MAMTC at the initial award of this project was to ensure coordination and interaction with the Fused Deposition Modeling Lab at Pittsburg State University. This inter .ction has been established through Kansas State University's Regional MAMTC Office with involvement of their field engineers. Gary Latham, a local field engineer, will serve to ensure this "interface" is developed beyond its preliminary stage. The Principal Investigator, Gary, and student assistants will work to produce at least one or more projects together with Pittsburg State University.

The CAMM-3 has the capability to be used to produce single and limited run printed circuit boards, small plastic and light metal production parts, scale models of equipment such as electrical motors, gas turbines, gears, pulleys, and casting dies. Once all equipment has been received and the system tested, a greater effort will be made to attempt several different operations. Another advantage related to possible projects using the CAMM-3 is its portability. The unit, along with its computer and cleanup equipment, can be transported in a standard veticle or a mini-van. This allows the CAMM-3 system to be transported and used as a teaching tool at the actual manufacturing site. This will be extremely valuable in "convincing" small manufacturers for the need of these type systems in their operations. The CAMM-3 could even be taken to remote job sites, displayed and used in small production applications.

\section{MODIFICATION OF EQUIPMENT}

In an attempt to minimize cost and further the CAMM-3's usefulness, engineering student assistants have been instructed to use their skills to design, build, or modify equipment to avoid purchasing "off-the-shelf" components that carried excessive price tags. Thus several modifications have been and will be completed on the original CAMM-3 equipment. One major change was to modify a drill chuck and shank to fit into an existing collet for the CAMM-3 mill. The CAMM-3 is delivered with a collet chuck system. This Roland product does not allow for the use of any tool that is not of metric shank size. In order to avoid purchasing Roland's expensive accessories, two additions to the original equipment were made.

1) A lightweight Jacobs drill chuck and shank have been purchased to facilitate the use of drill bits in the CAMM-3. Roland Digital does sell a spindle for the CAMM-3 that has a quarterinch drill chuck attachment. This Roland Digital attachment costs $\$ 400.00$ and requires changing the spindle in the CAMM-3. For a price of $\$ 56.78$, an acceptable drill chuck alternative was built and allows a way to change quickly from milling to drilling operations. This simple operation and modification saved over $\$ 340$ from Roland Digital's price. 
2) The CAMM-3 is set up to use all metric tooling. Roland does offer metric sizes of collets for $1 / 8$ " and $1 / 4$ ", but not 3/16." The engineering student assistant purchased an extra $4 \mathrm{~mm}$ collet from Roland Digital. This $4 \mathrm{~mm}$ collet was bored out to accept $3 / 16$ " shank tools. The use of tooling in standard sizes offers an opportunity to save additional monies in tooling. Roland Digital's price for tooling is approximately eight (8) times more expensive than tooling from other industrial suppliers.

3) Roland Digital offers a vacuum table for the CAMM-3. This vacuum table is designed to collect scrap material chips that are produced during the normal milling process. The vacuum table is connected to a standard commercial wet/dry vacuum. The table and associated wet/dry vacuum costs in excess of $\$ 2200.00$. By purchasing a portable dust collector for $\$ 200$ and fabricating a mounting bracket, over $\$ 2,000$ in savings was realized. Further, the portable dust collector has over five times the vacuum offered in a standard wet/dry vacuum.

\section{GOALS/PROJECTS UNDERTAKEN/AND FUTURE PROJECTS}

There are a number of goals to be accomplished through completion of this project. These goals will be accomplished either through the completion of outside projects or as specific tasks of the project itself. Further, a list of milestones has been developed to self-evaluate the effectiveness of the Principal Investigator, the MAMTC representative, and student assistants. Obviously, significant outside variables have an impact on what is accomplished with this project.

\section{GOALS}

1) Faculty, MAMTC engineers, and engineering students are to become proficient with all components and uses of CAMM-3 system and supporting software.

2) Test and evaluate feasibility of file transfer from CAMM-3 system to AMI systems.

3) Make contact with Pittsburg State University's Fused Deposition Laboratory through Gary Latham, MAMTC engineer. Discuss project development to share information and resources.

4) Test both the mechanical and electrical prototype capabilities of the CAMM-3.

5) Work with one or more Kansas companies on a specific project which assists in the design process. 


\section{PROJECTS UNDERTAKEN}

1) In September, the student assistant began looking in earnest for an outside organization with which to develop a project. The CAMM-3 mill and AMI's labs were to be used to prototype and produce a component. An opportunity was realized when the student assistant made contact with Kansas Wildlife and Parks biologist, Randy Rodgers. Mr. Rogers had designed a gauge that was in use by Kansas Wildlife and Park biologists. The guage determines the sex of ring-necked pheasant after they are killed and dressed. The gauge was used to measure the breast bone dimensions of the bird and was designed as a go/nogo instrument. Wildlife and Parks Law Enforcement Officials had already purchased these gauges from an outside producer who had made them out of a clear plastic material. Mr. Rodgers said breakage was a

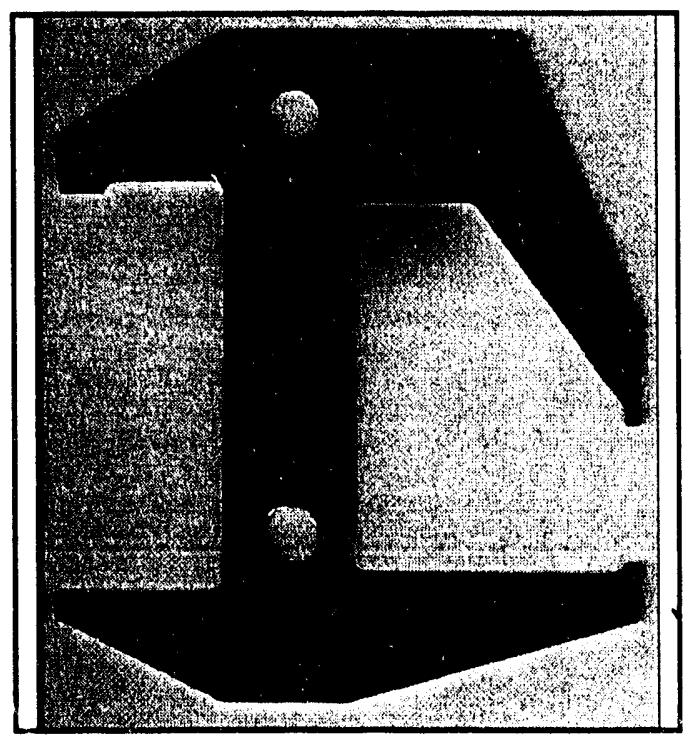
problem and requested the guagues to fabricated our of steel or aluminum material.

The student assistant began by utilizing the rough design drawings given to him by Randy Rodgers and reproducing a part with the needed dimensions. These drawings were completed in the SmartCam software package for ease of conversion to machine code. After about 1 hour of drawing and 3 days of milling several different trial designs, the student assistant produced an aluminum gauge that was sent to Randy Rodgers for his approval. Upon his receipt of the prototype, Mr. Rodgers called the student assistant and informed him that the design was well within his specifications and that he would contact the Wildlife and Parks Law Enforcement staff for their approval.

On October 15, 1993, Jeff Gayer, a member of the Kansas Wildlife and Parks Law Enforcement staff contacted the student assistant and placed an order for 40 gauges. They requested that the gauges be delivered by November 11, 1993 to allow for use on opening weekend of Pheasant hunting this season. The student assistant then contacted Dan McAnarney, AMI research assistant, to coordinate the production of the gauges with their Maho MH600 mill. Dan McAnarney told the student assistant that it would be best for him if the student assistant were to run the Maho mill instead of his staff due to their work load. This would give the student assistant the opportunity to follow the process from design to actually producing the final product as well as an opportunity to work with larger production equipment and test the prototype milling files on production equipment.

The design files that had been produced by the student assistant were taken over to AMI and Dan McAnarney examined them to ensure that they would be compatible with the Maho mill. Small changes in the files were required, mostly due to the student assistants lack of experience using SmartCam, but the basic design and dimensions were completely 
compatible with AMI's industrial system.

After these small changes were completed, the student assistant chose 1020 mild steel as the material to produce the gauges and production of the gauges began on October 29, 1993. During the production of the gauges there were no major problems with the design and only 6 gauges fell out of set dimension parameters. These 6 gauges were scrapped and replacements were produced to finish the order. The final gauge was completed on October 9, 1993. The Wildlife and Parks Commission received the first shipment of 30 gauges on November 5, 1993.

The Department of Energy - Site Operator Users Task Force requested several milled reproductions of supporting organization logos. These company logos were used as part of a poster display. This display and other items were shown at the Electric Power Research Institutes Second Annual Electric Vehicle and Infrastructure Conference held in Scottsdale, Arizona. The first step to be completed by the student assistant was the production of, or importing of, files into SmartCam that contained each organizations logos. This proved to be difficult and took several days of work to complete. The logo's that were not available in .DXF file format, or a format that was convertible to. $\mathrm{DXF}$, were actually produced by the student assistant from his own drawings. A cleanup process must be completed on all files that are imported into SmartCam. When files are imported into SmartCam they almost always contain extra information that is not required to create the tool files. This information must be

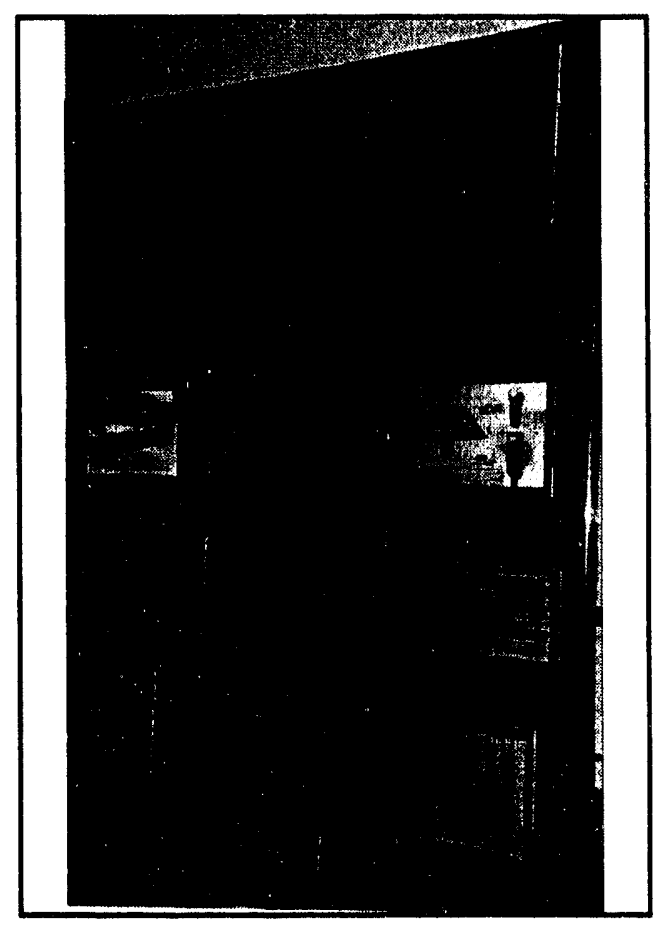
removed from the drawings so that the tool files will not contain data such as dimension or cut lines that may be represented on the design drawing. As soon as all of the logo files had been either created or imported, cleaned up, and properly converted into machine code for the CAMM-3 mill, the process of milling began. The logos were cut from $5 / 8$ inch oak boards with mills ranging in size from $3 / 16$ inch to $1 / 32$ inch. This allowed great detail to be produced in the milling operation. 
The student assistant also worked on a printed circuit design submitted by the EHV Corporation of Manhattan, Kansas. The design was given to the student assistant in an AUTOCAD file and then converted into a .DXF file by the student assistant that could be imported into SmartCam. The student assistant then began work in SmartCam to produce the tool paths that would be required to actually produce the circuit board with the CAMM-3 mill. Following several hours of work perfecting the software tool path design, the files were transferred to the mill and a prototype of the circuit board was produced. The main advantage offered by using the mill to produce the board is that, along with the milling of the traces, all drilling operations can be completed at the same time. This allows the drill points in the circuit board to be placed very accurately $(+/-.01 \mathrm{~mm})$, easing the mounting operations for components on the circuit board. This

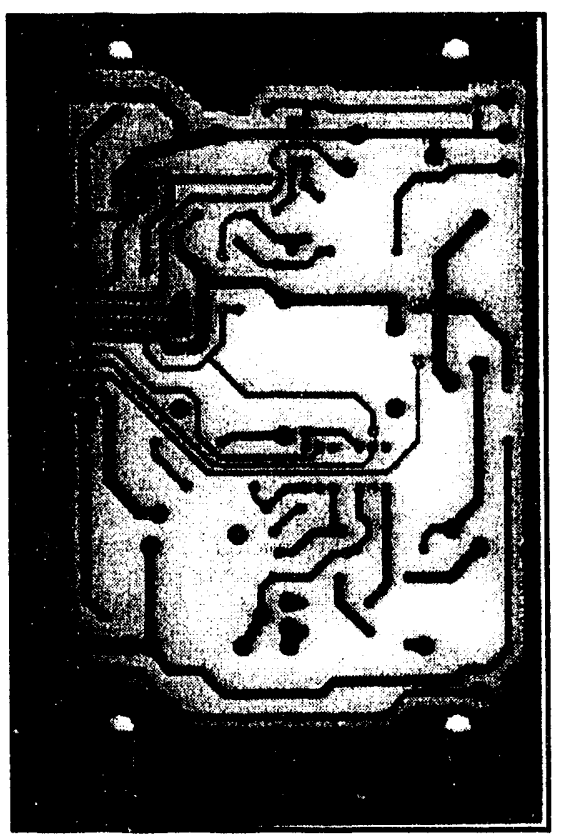
also ensures repeatability for the manufacturer. Upon receipt of the prototype board, EHV's engineers discussed some needed minor changes that should be made to the prototype board. Since the original files are very easy to manipulate, the suggested changes took minimal time, less than 1 hour. After these changes, the next prototype of the circuit board was ready to be produced. When the second circuit board was given to the EHV engineers, they said that the new board would allow them to complete component mounting and testing of the circuit board.

\section{FUTURE PROJECTS}

1) A project is currently being looked at by the student assistant and Gary Latham. This would involve developing a demonstration of the CAMM-3 mill that could be given at locations away from the K-State campus. This would involve the transportation of the mill and other necessary components to the demonstration site. This demonstration would facilitate the observation of operation and advantages of the mill to companies at remote locations and could possibly produce a prototype part for them at their location.

2) The student assistant is going to be involved with Engineering Open House at Kansas State University and will be designing several parts to demonstrate the abilities of the CAMM-3 mill to produce 3-dimensional parts from CAD files in a short amount of time. This will require that the student assistant enhance his knowledge of AUTOCAD, SmartCam and their interfacing capabilities.

3) The student assistant is working in conjunction with a graduate student in the 
Electrical Engineering department to produce a two-sided circuit board. This will require not only the repeatability of the circuit board design but will also challenge the student assistant to devise an accurate method of setting the tooling to the proper zero point to mill both sides of the circuit board in proper alignment.

\section{CONCLUSIONS}

To date, several of our original milestones and goals have been completed. The engineering student assistant has completed three projects using the CAMM-3 mill with excellent results. These projects have shown the flexibility and adaptability of the CAMM-3 milling system. The DOE SOUTF project that was completed shows the ability of the CAMM-3 mill to stand on its own as a useful tool in minor, limited production of parts and ideas. This is also demonstrated in the EHV circuit board project. Utilizing the CAMM-3 mill as a test device in the production and prototyping of small computer and circuit boards shows great promise, especially with the advantage of eliminating the use of chemicals in the prototype process. Time and cost are also minimized for both of these operations. The cost for EHV to hire out a small prototype run of circuit boards would have been very high and could take long periods of time. With the use of the CAMM-3 mill and its ability to use computer files, the operator has the ability to alter prototype designs with ease. The DOE SOUTF project here at K-STATE, was able to receive its custom poster in less than one week. These two projects show the flexibility of the system, but the best example of the use of the CAMM3 system is demonstrated by the Kansas Wildlife \& Parks project. This project shows the total range of the "Design to Production" process. This is exactly what the CAMM-3 system was intended to accomplish.

By exploring the uses of the CAMM-3 system further through future projects and developments we hope to assist MAMTC's work with Kansas' manufacturers. This will encourage and assist small businesses to venture out and develop new products. New ideas and the means to bring these new ideas to market is what the CAMM-3 project at K-STATE is all about. Those of us involved in the CAMM-3 project would like to thank MAMTC and K-State's College of Engineering for providing funding and overall support for this project. With continued support from these two organizations, along with AMI's support, this project will serve as a successful example of effective partnerships.

In conclusion, significant amounts of work have been accomplished in order realize the potential of the CAMM-3 system. The student assistant, Richard Rodgers is to be commended for his dedicated efforts in working with other University staff, MAMTC engineers, and company representatives. Without his dedicated effort, the CAMM-3 project would still be in the setup and configuration stage. All individuals involved have worked diligently to ensure that the projects undertaken have been finished in a professional and timely manner. This has allowed us to complete several projects and to realize many of our original goals for the project. Should anyone reading this report have any questions, suggestions for improvement, or criticism, please contact the principal investigator, Professor James Hague at (913) 532-5617 or facsimile (913) 532-5661. 


\section{APPENDIX A}

\section{DESIGN (WORKSTATION) COMPUTER SYSTEM}

486 DX2-66 Micronics MX-30 motherboard

32 Mbyte Random Access Memory (RAM)

256 K Static Cache RAM

\begin{tabular}{|c|c|}
\hline 1.44 Mbyte \& 1.2 Mbyte Floppy drives & $\$ 100.00$ \\
\hline Diamond Stealth Pro Video w/2 Mbyte RAM & $\$ 420.00$ \\
\hline Colorado Memory 250 Mbyte Tape Backup & $\$ 195.00$ \\
\hline Maxtor 330 Mbyte IDE Hard Drive & $\$ 358.00$ \\
\hline Microsoft Mouse & $\$ 75.00$ \\
\hline Tower Case / Keyboard / Power Supply & $\$ 320.00$ \\
\hline ADEX 20" color monitor & $\$ 730.00$ \\
\hline TOTAL SYSTEM COST & $\$ 4,308.00$ \\
\hline
\end{tabular}

\section{CAMM-3 CONTROL COMPUTER SYSTEM}

\begin{tabular}{|c|c|c|}
\hline $\begin{array}{l}486 \text { DX2-50 Micronics Gemini motherboard } \\
32 \text { Mbyte Random Access Memory (RAM) } \\
256 \text { K Static Cache RAM }\end{array}$ & $\$ 1,649.00$ & \\
\hline 1.44 Mbyte / 1.2 Mbyte Floppy Drives & $\$ 100.00$ & \\
\hline Diamond Speedstar 24x Video w/1 Mbyte RAM & $\$ 150.00$ & \\
\hline Colorado Memory 250 Mbyte Tape Backup & $\$ 340.00$ & \\
\hline Maxtor 170 Mbyte ESDI Hard Drive & $\$ 300.00$ & \\
\hline SmartCache Hard Drive Controller w/ 4 Mbyte Cache & $\$ 1,140.00$ & \\
\hline Microsoft Mouse & $\$ 75.00$ & \\
\hline Desktop case / Keyboard / Power Supply & $\$ 250.00$ & \\
\hline $\mathrm{ADEX} 20$ " color monitor & $\$ 730.00$ & \\
\hline TOTAL SYSTEM COST & $\$ 4734.00$ & \\
\hline
\end{tabular}




\section{APPENDIX A (continued)}

\begin{tabular}{||c|c||}
\hline \multicolumn{2}{|c|}{ ROLAND CAMM-3 MODELING MILL } \\
\hline CAMM-3 Mill system & $\$ 8,996.25$ \\
\hline $\begin{array}{l}\text { CAMM-3 Accessory kit "B" } \\
\text { ZC-1 Collet set } \\
\text { ZV-1 Machine Vise } \\
\text { High Speed Steel End \& Ball Mills (16) } \\
\text { Modeling Wax Blocks (20) }\end{array}$ & $\$ 796.00$ \\
\hline Collets for CAMM-3 (2) & $\$ 91.08$ \\
\hline Jacobs Drill Chuck \& Shank & $\$ 56.78$ \\
\hline Carbide End \& Ball Mills & $\$ 458.23$ \\
\hline Portable Dust Collector & $\$ 199.99$ \\
\hline 115 pc. Drill Bit sets (2) & $\$ 139.90$ \\
\hline \multicolumn{1}{|c|}{ TOTAL CAMM-3 SYSTEM COST } & $\$ 10,458.50$ \\
\hline
\end{tabular}

\begin{tabular}{||c|c|}
\hline \multicolumn{2}{|c|}{ ADDITIONAL EQUIPMENT PURCHASED } \\
\hline \begin{tabular}{|} 
Hewlett Packard Design Jet 650C w/16 Mbyte RAM \\
w/ necessary supplies
\end{tabular} & $\$ 7934.92$ \\
\hline ADEX 20" color monitor (1 unit) & $\$ 730.00$ \\
\hline SmartCam Software locks (2 units) & $\$ 1,100.00$ \\
\hline & \\
\hline & \\
\hline
\end{tabular}




\section{APPENDIX B}

\section{PROJECT SOFTWARE}

All software along with a brief description, whether purchased or provided at no cost to the project, is listed for reporting purposes.

1) AUTOCAD version 12 with AME (Advanced Modeling Extension)

Advanced drafting tool for development and layout of mechanical and electrical parts.

2) AUTODESK 3D STUDIO version 1

Advanced modeling software used to provide three-dimensional view of objects.

3) SMARTCAM version 7 (K-State Advanced Manufacturing Institute License \#06536) SmartCam is a sophisticated computer-aided manufacturing package. The software is in use at the Kansas State Advanced Manufacturing Institute. It provides design data on AMI's 4axis automated MAHO mill and the MORI-SEIKI live tool automated lathe.

4) MICROSOFT DISK OPERATING SYSTEM version 6.2

Basic operating system required by all IBM-AT compatible systems.

5) MICROSOFT WINDOWS version 3.1

Graphical interface software. Original purpose of this software was to make a "common" interface for various software packages. Overall purpose was to make users of computer systems more productive.

6) CENTRAL POINT SOFTWARE PCTOOLS FOR WINDOWS version 1

"Housekeeping" software for organizing and maintaining hard disk and data storage. Contains advanced diagnostic software to help in optimizing the performance of a computer's hardware and software.

7) WORDPERFECT version 5.2

Advanced text editor, desktop publisher, and graphical manipulation software package. Used for generating reports used in this project.

8) BASIC CAD/CAM

Software package provided by Roland for use with the CAMM-3 mill. This software package is not ideal for our use because the file format is not compatible with AMI software and would require extensive modification for file transfer. This software package is also not as "user-friendly" as the SmartCam software and requires extensive study to become proficient in its use. 


\section{Kansas State University Electric Vehicle Site Operator Program}

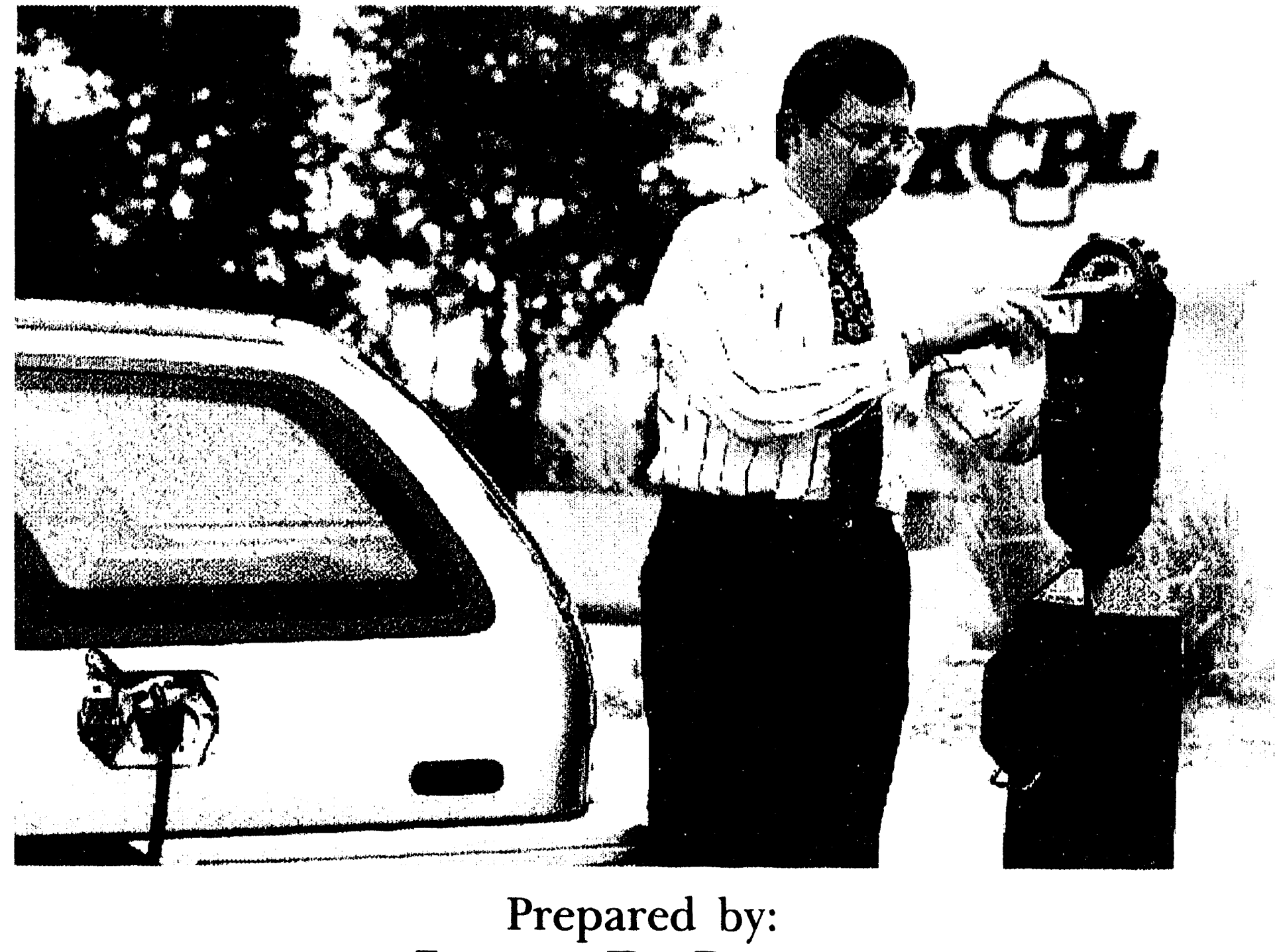

\section{James R. Hague}

Director, Electric/Hybrid Vehicle Program

Jarrett Thummel Jenifer Hague Richard Rogers

Service Technician Student Assistant Student Assistant

Kansas State University

219C Seaton Hall

Manhattan, KS 66506

Phone: (913) 532-5617

Fax: (913) 532-5661 

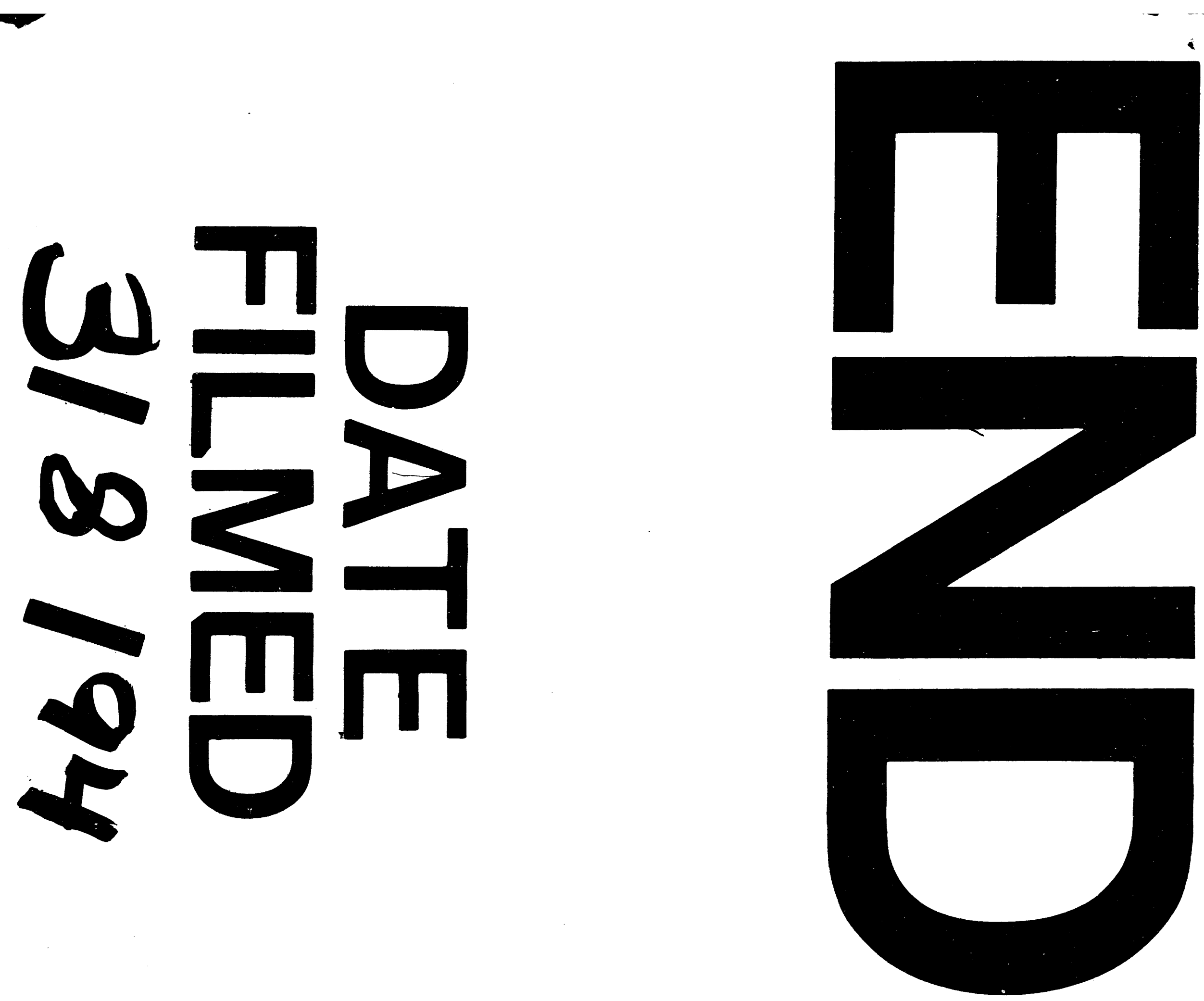
